\title{
LA CONCESION ADMINISTRATIVA DE SERVICIOS (Reseña histórica)
}

$351: 35.078$

\author{
por \\ Francisco Rodríguez de Haro \\ Doctor en Derecho y Diplomado en Administración local
}

SUMARIO: I. INTRODUCCION.-II. «REGALIAS» DE LA CORONA.III. ALBOREA LA CONCESION ADMINISTRATIVA: 1. PRIMERAS CONCESIONeS Públicas. 2. El SERVICIO de correos. 3. Precedentes del "SERVICIO PÚBLICO». 4. APARECE LA «EMPRESA CONCESIONARIA». IV. CONCESIONES COMERCIALES. LA «EMPRESA NACIONAL».V. LA MODERNA "CONCESION DEL SERVICIO PUBLICO»: 1. LA RAZÓN DE SERVICIO. 2. DESARROLlo DE La CONCESIÓN.-VI. CRISIS DEL REGIMEN CONCESIONAL: 1. CRISIS DEL CONCEPTO «SERVICIO PÚBLICO». 2. CRISIS DE LA CONCESIÓN DE SERVICIOS.

\section{INTRODUCCION}

No resulta fácil retrotraerse de un modo notable respecto al origen de la concesión administrativa de servicios considerada en sus actuales y específicos caracteres, pues su conformación como tal es una secuela de la revolución política que transforma la recia contextura del poder del Príncipe - absolutismo- en el flexible complejo del Poder del Estado liberal, que, como en el misterio cristiano de la Santísima Trinidad, es uno en esencia y trino en funciones: legislativa, ejecutiva y judicial, correspondiendo a la segunda - acción administrativa- el desarrollo del conjunto de servicios públicos demandados por la subsistencia del propio Estado 
(actividades policiales - de control y de fuerza-) que, por implicar ejercicio de autoridad, son indelegables en mano privada, o exigidos por necesidades de la comunidad política - líneas férreas, de navegación, etc.- que sí pueden ser objeto de cesión a particulares, entre otras formas jurídicas, por medio de la institución objeto de nuestro estudio.

La moderna estructura del Estado, asentada sobre principios morales y jurídicos que respetan al hombre como persona, sujeto titular de derechos y obligaciones a ejercitar libremente - sin más limitaciones que las impuestas por la ley-, o sea, el Estado de Derecho, es la que da origen a los conceptos de "Administración" y de su objeto: la prestación de los servicios públicos o actividades destinadas al cumplimiento de los fines generales; y, por consiguiente, para hacer la historia de la concesión administrativa de servicios públicos -como medio de prestación indirecta-, no podemos arrancar de los actos arbitrarios - no reglados- que, aun con carácter concesional, el Monarca, en uso de sus «regalías» - obtenidas por herencia o derecho de conquista-, hacía a sus súbditos; concesiones que eran territoriales o demaniales, no comparables con la estructura jurídica de nuestra moderna institución.

\section{II. «REGALIAS» DE LA CORONA}

En Andalucía, tierra donde nacimos y de nuestra más prolongada residencia, en la que se ubicaron los últimos reductos del dominio musulmán, la toponimia constituye aún el exponente de lo que fueron aquellas concesiones territoriales que hacían los monarcas - caudillos de la reconquista - a los señores, predominantemente castellanos y leoneses, que en los límites o marcas fronterizas con los reinos árabes, se asentaban como defensores de las mismas; quedando después, ya cuajada la unidad nacional (¡esfuerzo de ocho siglos de sacrificios y heroísmos, que algunos pretenden deshacer ahora en unos meses!), como poderosos terratenientes establecidos definitivamente en el país conquistado. $\mathrm{Y}$ así aparecen «los Estados» de Medinaceli y Medina-Sidonia, por ejemplo, en los membretes impresos - hasta no hace muchos lustros- en la correspondencia de esas Casas nobiliarias; como numerosísimos lugares responden aún a los apellidos de aquella cepa castellanoleonesa, como «Carvajales», «Benavides», "Arévalos», "de Haro», 
«Doña Aldonza», "Doña Mencía», «Doña Sancha», etc., cual vivencia perenne de tales regalías.

Villar Palasí (1), en su estudio histórico de la institución, hace referencia a esas antiguas concesiones territoriales por derecho de conquista, a las citadas "regalías» y a los «beneficia príncipis». Concesiones territoriales en las que no se otorgaba el pleno derecho de propiedad, sino un mero derecho transitorio y estrictamente personal: el objeto de la concesión eran «tierras fiscales", por lo que el Príncipe sólo podía ceder las facultades de uso y aprovechamiento que tenía en sus manos.

GASCÓN Y MARín (2) dice al respecto que «en el Derecho antiguo, la concesión equivalía a un privilegio que otorgaba a un particular derechos regalianos del Príncipe. Se negó que hubiere carácter de Derecho público en la concesión, y, a lo más, admitióse que hubiera una manifestación del Poder público en la posibilidad de otorgar la concesión, quedándose ésta, propiamente tal, relegada al campo del Derecho privado».

\section{ALBOREA LA CONCESION ADMINISTRATIVA}

\section{PRIMERAS CONCESIONES PÚBLICAS}

No obstante, bajo las tan repetidas facultades regalísticas, por exigencia de ciertas necesidades colectivas o públicas que no permiten una omisión por parte del Poder, entremezclándose el interès privado - del Monarca o de determinadas clases-y el público $\circ$ del común, en negocios a veces de una amplitud mercantil y política de gran trascendencia, asoma su faz la fórmula concesional de carácter público, aunque confusa en sus elementos esenciales (concedente: ¿el Rey o el Estado?; objeto: ¿negocio real o público?, etc.), pero que constituye un indudable anticipo o embrión de la figura que se conforma y perfecciona jurídicamente en los Estados contemporáneos.

Es decir, que los actos del Monarca absoluto no se podrían considerar sino acciones arbitrarias, aunque justificadas si queremos,

(1) aConcesiones administrativas». Enciclopedia Juridica SEIX, tomo IV, Barcelona, 1952.

(2) Tratado de Derecho administrativo. Ed. Reus, 1952. 
por una tradición o costumbre, no legitimadas por el Derecho público (si acaso por un "fuero" o norma de excepción y privilegio), inclinadas por eo al favor y al beneficio graciable; y hasta que no se impone el Derecho, estructurando el Estado, y dentro del ordenamiento jurídico se perfilan los ámbitos competenciales de los organismos estatales, no aparece la regulación de la actividad administrativa - «Administración»- por el Derecho administrativo, y, dentro del mismo, la reguladora y legitimadora del acto concesional con todos sus elementos: sujeto activo y pasivo — concedente y concesionario-, objeto -obra y/o servicio-, así como el condicionado jurídico y económico.

\section{El SERVICIO DE CORREOS}

Bien merece un enunciado propio este servicio, que, en las investigaciones a nuestro modesto alcance, nos ofrece las primeras manifestaciones de la institución concesional en su faceta de gestión pública.

Así, en la Baja Edad Media —según Toledo Guirau- (3), el servicio de correos en el Reino de Valencia, por ejemplo, tiene en principio el carácter de provisión de empleo público con fijación de salario, obligación de vestir uniforme, etc., de modo que "para ser admitido a últimos del siglo XIII un individuo como correo de la Casa Real, trasladada frecuentemente de unos sitios a otros de la Confederación aragonesa, el Tesorero Real remitía al Escribano Secretario una certificación haciendo constar que el Rey aceptaba los servicios de determinada persona en las mismas condiciones que los demás existentes».

Pero cuando el servicio se extiende no ya por necesidad de enlace de la Casa Real con autoridades o corporaciones ausentes, sino por la demanda de una vida comercial en auge, el otorgamiento de este servicio va tomando los caracteres de una concesión de servicio público.

(3) Los Correos en el Reino de Valencia. Edición del Excmo. Ayuntamiento valenciano, 1948, pág. 8. 


\section{PRECEDENTES DEL «SERVICIO PÚBLICO»}

Dice TOLEDo en su obra reseñada (págs. 8 y 9), cómo aparecen ya los primeros jefes $\mathrm{u}$ hostes de correos y las propuestas hechas por la Bailía, Diputación y Jurados de la Ciudad para ejercer el cargo de hoste, sancionadas por el Rey; de modo que "para el desempeño de la jefatura se necesitaba licencia real. Aquellos hostes cuya misión no sólo se limitaba a despachar correos en servicio oficial de la Cancillería, sino que los ofrecía asimismo a los jurados y otros representantes del pueblo, a los mercaderes, a los señores con jurisdicción y a cualquier otra persona o entidad que pudiera necesitarlos». "En 1428 el Consejo Municipal nombró para correo de la ciudad a Jaime Barta, sin salario alguno, pero con la obligación de llevar "bustia" en el brazo con las insignias correspondientes». Y dice también Toledo (pág. 11): "Por privilegio especial de Juan II de Aragón, dado en Zaragoza en 21 de marzo de 1461 y letras ejecutorias de igual fecha dirigidas al Baile general, en atención a los muchos servicios prestados por el hoste Benito Meseguer y accediendo a las súplicas de algunos familiares del Rey, éste le concede en exclusiva la regencia del libro de Correos, sin salario anual alguno, pero con las ganancias y obvenciones acostumbradas al oficio y regencia de dicho libro».

Es decir, que al nombrado no se le asigna salario alguno, lo que excluye la característica fundamental de función o empleo, pero sí con las ganancias y obvenciones acostumbradas, lo que implica una percepción de derechos preestablecidos (hoy "tarifas») y en exclusiva, o sea, con monopolio.

Podemos, pues, estimar que ya aparece en el siglo xv este otorgamiento con los visos de una concesión de servicio público. El propio Toledo lo aprecia así cuando habla (pág. 13) del «... privilegio de concesión" fechado en el palacio real de Valencia el día 2 de noviembre de 1472 sobre este servicio; y si no siempre se designan los hostes sin percepción de salario, la existencia de varios casos, como los indicados por nosotros en la obra citada, muestran ya el apuntamiento o apertura hacia una nueva fórmula que tiene, como decimos, caracteres de concesión de servicio público. 


\section{APARECE LA «EMPRESA CONCESIONARIA»}

Es interesante en tal sentido la referencia que hace Toledo (página 24) a unas provisiones de Fernando el Católico, en 12 de enero de 1488 , sobre la concesión «solicitada por los mayorales de la Cofradia y Compañia de Correos para lograr el mayor perfeccionamiento del servicio y utilidad social de la Cofradía»; con lo que aparece aquí la fundamentación moderna de muchas concesiones, basada en el interés social, acentuándose ese carácter monopolístico del servicio de correos cuando en 1505, por una Real Orden, se nombra a «Francisco de Tassis, capitán y maestro de postas, mandándole establecerlas con buenos caballos a Francia, España y Alemania...», de modo que, vencida la dura oposición de los hostes de Barcelona y Valencia y correos de otras ciudades, el nombrado - con otros familiares- reúne en sus manos el monopolio de las postas de Alemania, Italia, Países Bajos y España - territorios de soberanía de su benefactor Carlos I-; y cita también cómo a la muerte de Francisco de Tassis, "Doña Juana la Loca y su hijo el Rey Don Carlos, por su providencia firmada en Zaragoza a 28 de agosto de 1518", confirman a los sobrinos de aquél en el cargo, para todos sus reinos y señoríos "durante sus vidas o del que más viviere», concediéndoles la nacionalidad española; así como prohibiendo en todas las cosas concernientes al servicio real, bajo la pena de cien mil maravedíes, despachar para cualquier parte o lugar, pliegos o viajes que no fuesen cursados por dichos correos mayores, quienes habían de recaudar el importe de los viajes correspondientes para pagar a los correos y retenerse sus derechos, prohibiéndose a los contadores mayores tomar nota de gasto alguno que se hiciere por estos servicios, excepto cuando mediaren las cartas de pago de Bautista, Mateo o Simón de Tassis (sobrinos del primitivo concesionario Francisco de Tassis).

Vemos ya, según lo expuesto, cómo aparecen configurados los elementos concedente -el Rey como titular de la soberanía y figura precedente del moderno poder ejecutivo o "Administración»-; concesionario - ya en forma de empresa, como la citada "Cofradía y Compañía de Correos», ya individual, como los miembros de la familia Tassis-; el monopolio -exclusividad del concesionario en la prestación del servicio y en la percepción de sus «derechos», con- 
forme a lo preestablecido por la costumbre, o sea, a lo tarifado «de facto»-.

\section{CONCESIONES COMERCIALES. LA «EMPRESA NACIONAL»}

Notemos que en este período histórico se va preparando ya la transformación finalística de los Estados modernos, por imperativo de las necesidades que afloran en el orden interno y externo de la sociedad política; pues así como lo expuesto implica, en orden a la misión clásica de la Administración, un anticipo - bastante adelantado en el tiempo, aunque en casos aislados, doctrinal y jurídicamente imperfectos- de los futuros conceptos del servicio público y de su instrumento de prestación que hoy estudiamos, también nos brinda en orden a la actividad económica o mercantil, que tanto llena en nuestros días de contenido a esa Administración, un precedente histórico en la expansión comercial de las potencias marítimas de entonces, a base, asimismo, del régimen concesional.

El "Hansa teutónica», Portugal, España con los Fugger o «Fúcar» y los Welser, y Holanda con su Compañía de las Indias Orientales, ¿no implican una gama de concesiones mercantiles monopolísticas, fuertemente protegidas por sus marinas militares, que encubren fines fiscales y políticos, ya que al "negocio" de los concesionarios se sumaba un doble interés estatal: el de la expansión de su poder -el Imperio- y el de nutrir la Hacienda pública en su enorme demanda de dinero para hacer frente a los gastos de la Casa Real y al mantenimiento de las fuerzas militares?

$\mathrm{La}$ variedad e importancia de estas concesiones las analiza PÉrez MoReno (4) al enjuiciar su forma jurídica, por países, del siguiente modo: "El comercio del Estado" se traduce en la iniciativa de éste "en la creación de las Compañías, en la fuente de financiación de las mismas, en la articulación y fundamento de la participación estatal en la dirección y en las ganancias y en la forma de atribuir las importantes funciones políticas a las organizaciones creadas». Y así tenemos: Portugal: "El comercio se realizaba por cuenta y riesgo del Rey y con barcos propiedad de la Corona. Las funciones políticas se retenían por los funcionarios». Francia (Col-

(4) La forma juridica de las Empresas públicas. Sevilla, 1969. 
bert): «... el Estado era el empresario en el comercio exterior». Por su iniciativa se creaban las Compañías. El capital lo suministraba el Rey de las arcas del Estado y presionando sobre los medios financieros para obligarles a suscribir acciones (caso de la Compañía de Indias Orientales). Inglaterra: «... a diferencia del régimen inglés, en el cual el Rey obtenía ganancias a cambio de los privilegios que otorgaba a las Compañías». Holanda: La fórmula era híbrida - Compañía de Indias Orientales (1602) y de las Indias Occidentales (1621)-: unidad de empresa con diversidad de organismos separados y una amplia independencia como centros de importación y relaciones, denominados Cámaras. Los directores de éstas llegaron a ser los mismos burgomaestres de las ciudades donde las Cámaras tenían su sede. España: La creación de las «Reales Compañías» es tardía. "La influencia decisiva del poder real en el nacimiento, desarrollo y extinción de las Compañías es patente, a tal punto que quedan éstas vinculadas a los fines públicos, como organismos de este carácter. Aunque existen accionistas, predomina en las decisiones importantes el interés público».

Por lo general, junto a la atribución de personalidad, a las Compañías se les concedían privilegios monopolistas e importantes funciones políticas.

El profesor Algarra (5) nos refiere que «Antonio Fugger (14931560)..., gracias a su influencia cerca de Carlos V, a quien había pagado los 300.000 florines a que se elevaron los gastos de su coronación, obtuvo factorías en Venezuela y franquicias aduaneras en América, iniciando así la política comercial alemana. Al mismo Carlos V, de acuerdo con la Casa Welser, hizo un préstamo de 1.200 toneladas de oro (unos nueve millones de pesetas). En 1630, Marcos y Cristóbal Fugger prestaron grandes cantidades a Felipe II. En la imposibilidad de devolver estas sumas, dichos reyes españoles cedieron a los Fugger minas de oro en Alemania y las de mercurio de Almadén".

Existía, pues, un recíproco interés en estas concesiones monopolísticas: por parte del concedente la expansión de su imperio político y económico con una fuente de considerables ingresos efectivos para el Tesoro $y$, en caso de apuro, de fácil cobertura de "empréstitos»; $y$, por parte de los concesionarios, un «negocio re-

(5) Traducción de la Historia de la Economia de J. ConRad. Ed. Montserrat, Barcelona (nota en la pág. 29). 
dondo», sin tasa en el precio de los artículos, amparado o protegido por la armada real.

VIllar Palasi (ob. cit., pág. 610), con referencia a los siglos XVII y XVIII, señala un fenómeno de extraordinaria importancia: cómo «... el Estado se apodera de la economía..., el Estado crea las grandes áreas económicas, realiza política de población y tráfico, toma en sus manos las aduanas, lleva a cabo guerras económicas, establece industrias y funda fábricas; en una palabra, sugiere y fomenta, regula y dirige. La economía del siglo XVII al XVIII se llama mercantilista y es organizada por el Estado". Y contemplando esa actividad dirigente y absorbente del Estado, hay que preguntarse: ¿qué diferencia existe entre aquella política económica y la que hoy nos presenta el Estado como productor de bienes de consumo?

\section{LA MODERNA «CONCESION DEL SERVICIO PUBLICO»}

\section{LA RAZÓN DE SERVICIO}

Como consecuencia de tal actividad rectora de la economía, el propio autor citado (misma pág. 610) dice: «Se produce tras toda esta evolución un hecho, si no nuevo en esencia, sí al menos en cuanto a la intensidad con que se deja sentir: la aparición de la concesión del servicio público, alrededor de la cual ha girado tradicionalmente el Derecho administrativo clásico. El Estado, sintiéndose más fuerte ante la necesidad en que se hallaba dentro de su proceso evolutivo, hacía despertar su impulso activista, auspiciado por la Revolución francesa. La Revolución, al suprimir todos los cuerpos intermedios, dejó al individuo aislado frente al Estado. Al suprimirse los señoríos jurisdiccionales, los servicios generales que a su través se prestaban pasaron en su responsabilidad al Estado».

En cuanto a nuestro país, expone cómo esa «idea fuerza» fue introducida por Jovellanos, Floridablanca y Aranda, ocurriendo que el sistema concesional - "término medio" entre la gestión directa y la actividad privada - cobra un fuerte auge; restringiéndose las concesiones demaniales como fruto de las regalías señoriales y surgiendo la figura del servicio público concedido a particulares, al que el ambiente liberal del momento le presta gran calor. «El 
Estado liberal -dice- abominó de la raison d'Etat, en cuanto artilugio incompatible con el Estado de Derecho que le era circunstancial. Mas edificó algo que no era por razón de herencia o traducción de lo mismo, la raison du service, para justificar el control discrecional de la Administración sobre los concesionarios».

Y ¿qué más da al respecto dentro del Estado de Derecho: la «razón de Estado» o la "razón de servicio?; porque si la primera se matiza por un predominio del Poder con el peligro de una arbitrariedad interpretativa y justificativa de la intervención, y la segunda aparece fundamentada en una evidente necesidad o demanda social, ambas, hoy, las creemos casadas en una razón fundamental de gran peso moral, cual es el interés de la comunidad o bien común, verdadero asiento básico e insoslayable no ya del elemento Poder, sino del propio ente: el Estado.

\section{DesarRollo de LA CONCESIÓN}

Es en el siglo XIX cuando esa fórmula jurídica de la concesión administrativa cuaja y se desarrolla extraordinariamente, consolidándose como un instrumento indispensable a la Administración para poder afrontar la prestación de servicios - con o sin ejecución de obras- que por sí sola no podría financiar, ni, por tanto, abarcar.

Aparecen en sucesión casi ininterrumpida nuevos y utilísimos inventos -electricidad, telégrafo, teléfono, máquina de vapor, etcétera-, que se traducen rápidamente en el planteamiento de necesidades colectivas que el Estado no puede hurtar a la comunidad, y a cuyo auge contribuyen las exigencias del gran desarrollo industrial y comercial, secuela del empleo de las nuevas máquinas; es decir, que se plantean paralelamente a aquellas demandas, las de prestación por la Administración de modernos y costosos servicios.

A ese desarrollo industrial le acompaña, paralelamente, el económico, y la necesidad de distribuir ágilmente la gran producción manufacturera demanda modernos y poderosos medios de transporte, tanto por mar - flotas movidas a vapor-como por tierra -ferrocarril-, lo que implica a su vez la realización de costosas obras públicas. Y el Estado se halla impotente para afrontar con sus presupuestos la ejecución de todo un vasto complejo de obras 
e instalaciones, por lo que ha de apelar al capital privado, a la colaboración de las grandes empresas que, subrogadas en ese cometido fundamental, realizan las obras de estructura, montan la maquinaria y todo el material móvil necesario al servicio, para, en compensación, explotar éste comercialmente.

Y así, salvo aquellos que se consideran de trascendente influencia en la salvaguarda de la seguridad nacional, como la red telegráfica, la fabricación de armamento -en el que juega mucho el secreto militar-, etc., casi todos los demás servicios públicos (ferrocarriles, puertos, canales de riego y abastecimiento de agua potable a poblaciones, etc.) pasan a manos de empresas privadas, algunas tan poderosas que juegan un papel trascendente en la economía nacional.

En la esfera de la Administración local, ese panorama es aún más amplio en cuanto al objeto de la concesión, pues se extiende al abastecimiento de aguas, que, en nuestros días - por el crecimiento desorbitado de las grandes ciudades, que demanda inmensos caudales de consumo-, impone la ayuda financiera del Estado a los proyectos de captación y conducción; al suministro de alumbrado, a la prestación de transportes urbanos - aquejados de déficits crónicos que también ha de afrontar la Hacienda central一, a la construcción de mercados, mataderos, etc.

Es decir, que este "endoso" del servicio público a la empresa privada es realmente necesario y conveniente, pues evita a la Administración la contracción de deuda pública, que el capital privado no cubriría fácilmente, tanto por su gran volumen (sumadas las necesidades crediticias del Estado, Provincia y Municipio), como porque los réditos de los valores públicos sólo ofrecen incentivo al modesto y prudente ahorro, pero no al capital fuerte que aspira a dividendos pingües, a un positivo incremento de su caudal y no a la cuasi-congelación de sus inversiones -erosionables por la desvalorización monetaria-, aunque con ello corra mayores riesgos.

De todo ello resulta, pues, la extraordinaria utilidad que para la Administración representa el instrumento jurídico de la concesión del servicio público. 


\section{CRISIS DEL REGIMEN CONCESIONAL}

\section{CRISIS DEL CONCEPTO «SERVICIO PÚBLICO»}

Por lo que respecta a nuestros días - como dice Villar Palasf (ob. cit., pág. 691)-, después de dos guerras mundiales, se produce una «masificación de necesidades»; siendo las propias exigencias del súbdito, psicológicamente ante las coyunturas económicas bajas, lo que ha hecho que el Estado vaya asumiendo en sus manos, progresivamente, mayor cantidad de funciones. "El Estado, como ha dicho Drago, deja de ser dominado únicamente por los conceptos de poder público y de los servicios públicos. La evolución política le confiere tareas nuevas, para las cuales utiliza fórmulas jurídicas nuevas o preexistentes. Los Estados modernos se han visto obligados, como dice Bloch, apartándose de todas las cuestiones doctrinales, $y$, cualquiera que sea el régimen político imperante en ellos, a extender y expansionar siempre la noción raíz del servicio público y de la concesión administrativa. Esta extensión desmesurada de un concepto que había ya cristalizado en su misma esencia es cabalmente lo que ha producido la actual crisis del mismo, no en sí, sino en cuanto a su idoneidad para comprender la total realidad políticoadministrativa de hoy".

En efecto. Ya hemos visto en el curso de este modesto estudio histórico que el contenido de la concesión fue en un principio la cesión de uso de territorios -que se amplió después a ciertos beneficios en provecho del concesionario-, lo que en este aspecto aún subsiste en la concesión demanial o de bienes públicos - siempre, antes y ahora- sin traspaso del dominio y con un límite por bajo de los cien años para evitar la prescripción inmemorial; y hemos apreciado que en la otra concesión, la de servicios, su otorgamiento al concesionario no se hace con miras a su beneficio -aunque justa y necesariamente haya de tener su compensación económica-, sino al beneficio de la comunidad, para la realización de obras y servicios (como en la construcción y explotación de líneas ferroviarias), de servicios sin obra previa (transportes por carretera, v. gr.); y en esa directriz de evolución creciente es cuando van surgiendo nuevas necesidades colectivas consolidadas que la Administración no puede dejar de proveer si no lo hacen los particulares (subsidiariedad). Y si facilitar a los ciudadanos un servicio de ferro- 
carriles o autobuses es obligado, no lo será menos el que la Administración, por razones de interés público (directo o de satisfacción de una necesidad colectiva, o indirecto - para evitar traerlo del extranjero "a peso de oro" y con detrimento de la economía nacional que ha de pesar sobre todos-), promueva y proteja la producción de bienes de consumo, otorgando las llamadas concesiones industriales.

Y es ahí donde surge la crisis doctrinal del contenido (servicio) y, como consecuencia, la del continente (concesión); pues así como el contenido clásico de la concesión es "un servicio público» o aprovechamiento por el usuario de actividad o prestación inmaterial, de algo impalpable (o si palpable, consumible, como el agua, v. gr.), ya que las obras e instalaciones -elementos materiales- son medios instrumentales y no el objeto de la prestación, en la concesión manufacturera el objeto de la misma es servir al público un bien material o tangible. Es decir, que en la clásica concesión de servicios, los medios son materiales y el objeto inmaterial, y en la concesión industrial los medios y el objeto son materiales.

GARRIDO Falla (6), respecto a esta última dice que sus actividades «están destinadas al público», y en ello «hay un interés público implicado", por lo que se produce un intervencionismo de la Administración, justificado, a través de la «autorización» que, por su condicionado, se asemeja al clausulado de una concesión de servicio público, pero al que una nueva doctrina califica de «servicio público impropio o virtual».

\section{CRISIS DE LA CONCESIÓN DE SERVICIOS}

Insistiendo y como conclusión, mientras que la concesión de servicio público entra de lleno en los fines genuinos, que son la razón de ser del ente concedente - la Administración-, puesto que están fuera del comercio o de los derechos naturales del ciudadano, la asunción por sí o mediante concesión de las actividades que entran en el campo de las competencias y derechos privados es un fenómeno actual que pone en franca crisis nuestra institución: de un lado porque se desnaturaliza la pureza u ortodoxia de su contenido $\mathrm{u}$ objeto -el servicio público puro-, y, de otra, porque la nueva

(6) Tratado de Derecho administrativo. Madrid, 1962. 
versión de ese objeto sólo es admisible como subsidiaria de la iniciativa privada; todo lo cual constituye una distorsión de la figura clásica, una crisis de la misma.

Hasta en el orden internacional, en el que esta institución vino siendo el instrumento más ágil e insustituible para que los pueblos pobres pudiesen fomentar la investigación y explotación de sus recursos naturales, utilizando los medios financieros y tecnología de las naciones más adelantadas (grandes empresas petrolíferas, v.gr.); últimamente, por el relativo progreso cultural de aquellos países subdesarrollados y su creciente celo emancipador, se han ido abordando las nacionalizaciones de tales negocios - no siempre de un modo justo en orden a la debida compensación de los intereses empresariales o privados colisionados con el interés público del Estado concedente; sin que los entes concesionarios, al no ser sujetos de Derecho internacional, hayan estado suficientemente protegidos, ni jurídicamente ni "manu militari", pues las viejas fórmulas intervencionistas (desembarcos y ocupaciones territoriales por las marinas militares) ha tiempo que la opinión pública mundial las reprueba como escandalosas e intolerables. La figura concesional ha quebrado también en este campo. 